\title{
ASSOCIAÇÃO ENTRE FATOS GEOMÓRFICOS E OS DOBRAMENTOS DE FUNDO NA EVOLUÇÃO DE UMA REDE DE DRENAGEM NA MARGEM ATLÂNTICA DO PLANALTO BRASILEIRO: O CASO DA BACIA HIDRÓGRÁFICA DO RIO BENEVENTE - ES
}

\author{
Roberto José Hezer Moreira Vervloet* \\ Jurandyr Luciano Sanches Ross**
}

Resumo: As questões geomorfológicas tratadas neste artigo se referem à parte conclusiva da pesquisa intitulada Condicionantes morfológicos e estruturais na dinâmica fluvial da bacia hidrográfica do Rio Benevente - ES, cujo principal objetivo era investigar os fatores litoestruturais, tectônicos e morfológicos que condicionam a evolução da rede de drenagem da bacia do Rio Benevente, no sul do estado do Espírito Santo. No referido artigo, são apresentados os dobramentos de fundo, estudados por Ruellan (1952), e os níveis de base local e regional de erosão que condicionam a evolução da rede de drenagem, responsável pela dinâmica e gênese de subcompartimentos de relevo que estão intimamente associados à relação litoestrutura tectônica-relevo-evolução de canais fluviais. Este artigo é uma homenagem ao pioneirismo de Ruellan, no que diz respeito à descoberta da participação dos dobramentos de fundo na interpretação de compartimentos de relevo gerados a partir da dissecação hidrográfica.

Palavras-chave: geomorfologia estrutural, evolução de drenagem, compartimentação geomórfica, hidrogeomorfologia e hidráulica.

\section{ASSOCIATION BETWEEN GEOMORPHIC FACTS AND FOLDING GROUNDWORK THE EVOLUTION OF A DRAINAGE NETWORK ON THE ATLANTIC MARGIN OF THE BRAZILIAN PLATEAU: THE CASE OF THE WATERSHED OF THE RIVER BENEVENTE - ES}

\begin{abstract}
The issues addressed in this article refer to the concluding part entitled research Morphologic and Structural Dynamics Constraints in the river basin of Rio hydroghaphy Benevente - Espirito Santo which aimed to investigate the lithostructural, tectonic, morphologic factors as constrain the in evolution of the drainage network of Benevente, river basin located in the south of Espírito Santo, state, Brazil. In this article it's present the fold of background, studied by Ruellan (1952), set out the basic levels in local and regional erosion process, while also affects the evolution of the drainage network, as responsible for the dynamics of sub-compartments relief associated to lithostructural interface tectonic-relief-fluvial channels evolution. This article does homage to the pioneering work of Ruellan regarding the geomorphologic studies about Brazilian territory.
\end{abstract}

Keywords: structural geomorphology, evolution of drainage, partitioning geomorphic, hydrogeomorphology and hydraulic.

\section{Introdução}

A busca da origem e dos conhecimentos relativos à evolução dos grandes compartimentos de relevo do Planalto Atlântico do Brasil têm sido objeto de grandes discussões entre geomorfólogos e geólogos desde a década de 1940. Foram muitos os trabalhos realizados sobre as mais diferentes óticas e abordagens sobre esses planaltos de fachada. Podem-se agrupar esses trabalhos em quatro linhas de estudos, a saber: (a) uma que trabalha com modelos geomorfológicos erosivos com implicações tectônicas, como De Martonne (1943; 1944), Freitas (1951a; 1951b), Ruellan (1944), King (1956), Ab'Sáber (1964), Birot (1959), Almeida e Ponçano (1993), Almeida e Carneiro (1998) e Azevedo Jr. (1991); (b) a dos que aplicaram o enfoque morfoclimático

\footnotetext{
* Doutorando do Programa de Pós-graduação em Geografia Física da FFLCH-USP. E-mail: rvervloet@usp.br.

** E-mail: geousp@usp.br.
} 
baseado nas mudanças climáticas Quaternárias, como Bigarella e Ab'Sáber (1961), Bigarella e Mousinho (1965), Bigarella e Andrade (1965) e Bigarella, Andrade Lima e Riehs (1975), entre muitos outros; (c) a que não é fundamentalmente geomorfológica, mas de enfoque predominantemente tectônico associado a elementos geomórficos para pesquisar a importância da tectônica iniciada no Paleógeno e suas repercussões na gênese dos relevos do planalto, como Riccomini (1989), Saadi (1993; 2000) e Hasuy (1990), entre outros; e (d) a que trata dos agentes geoquímicos destacando a formação, por processos químicos, as feições geomórficas e até as superfícies aplainadas embutidas entre os grandes compartimentos de relevo regionais (Serra do Mar e Mantiqueira), como os trabalhos de Filizola e Boulet (1993; 1996), Filizola (1993) e Coltrinari (1992; 1997; 2003), este último fazendo uma formidável recuperação das interpretações de De Martonne $(1943 ;$ 1944) quanto à gênese da superfície Neogênica, embutida entre a Serra da Mantiqueira e Serra do Mar.

Convém lembrar que todos esses trabalhos foram realizados em porções das diversas serras existentes no Planalto Atlântico e em outros setores do mesmo, e trouxeram contribuições muito importantes para o conhecimento dessas "terras altas".

Entretanto, é possível observar nestes trabalhos e, principalmente, nas pesquisas mais recentes, a partir dos anos 1990, uma ligeira ausência quanto à atuação dos sistemas de níveis de base, controlando as fácies de dissecação da superfície, da evolução desigual dos sistemas fluviais e, principalmente, a participação dos dobramentos de fundo, postas pelas pesquisas de Ruellan (1951a; 1951b; 1952a; 1952b; 1953) na década de 1950. Esse geomorfólogo francês apresentou importantes diretrizes de estudo sobre a participação das estruturas antigas no condicionamento do modelado da fachada atlântica, sobretudo para a fundação de uma geomorfologia estrutural brasileira. Tais sistemas atuariam através dos grandes anticlinais e sinclinais de fundo, estabelecendo níveis de soleiras rochosas que funcionariam como pontos de interrupção das drenagens seccionantes das estruturas mais antigas (Proterozoicas), criando sistemas de níveis de base e condicionando a dissecação diferencial do relevo, através das redes de drenagens instaladas a partir do Oceano Atlântico em direção as terras do Planalto Atlântico.

Este artigo objetiva apresentar o papel e a importância que esses sistemas de dobramentos de fundo têm no condicionamento da evolução das redes de drenagem que compõem a hidrografia da Bacia do Rio Benevente, uma das várias bacias hidrográficas da fachada atlântica, no Estado do Espírito Santo, e o controle litoestrutural exercido nos compartimentos de relevo da mesma, enfatizando a evolução diferencial da drenagem sobre estruturas de organização complexa e antiga (Proterozoicas).

Convém alertar para o fato de que este artigo não se baseia, somente, e simplesmente, nas pesquisas de Ruellan, realizadas na década de 1950, para investigar os dobramentos de fundo, mas procura, a partir das diretrizes teóricas e empíricas deixadas por esse autor, somadas a outros métodos e técnicas de pesquisa, descobrir quais as repercussões geomórficas 
dessas estruturas no controle e evolução dos sistemas de drenagem através de uma evolução em processo.

\section{Método e procedimentos técnicos}

O processo investigativo desta pesquisa baseou-se no método da associação e indeterminação geomorfológica de Leopold e Langbein (1970), acompanhado de procedimentos técnicos de cartografia geomorfológica, construção de perfis morfogeológicos, compilação de dados de parâmetros hidrográficos (em número de 12 parâmetros coletados) das redes de drenagem das sub-bacias, dados morfométricos e trabalhos de campo.

Este método consiste em um tipo de lógica científica, baseada numa construção argumentativa de raciocínio, a partir da associação de diferentes fatos geomórficos cartografados e compilados. Para se conduzir a linha de raciocínio realizou-se compilação de informações sobre os fatos geomórficos investigados.

Assim, adotaram-se os seguintes procedimentos técnico-operacionais:

(1) compartimentação geotectônica e geomorfológica (cartografia das feições geomórficas, unidades, grupos de formas de relevo e feições fluviais em escala adequada);

(2) compilação de dados de parâmetros hidrográficos das redes de drenagem (associados as respectivas subbacias hidrográficas e compartimentos morfológicos) e dados morfométricos;

(3) construção de vinte e um perfis morfogeológicos (associando características litoestruturais e litotectônicas no controle dos grupos de formas e sistemas de drenagem em evolução) distribuídos ao longo da bacia;
(4) trabalhos de campo, onde se procurou corrigir e fazer controle dos fatos geomórficos cartografados e averiguar in loco os possíveis elementos litoestruturais e litotectônicos que atuam condicionando os grupos de formas de relevo e as respectivas redes de drenagem, bem como possíveis reativações holocênicas de estruturas (sistemas de falhas e fraturas).

Ao longo deste processo investigativo as informações geomórficas e dos parâmetros hidrográficos e morfométricos foram cartografados e compilados com o objetivo de se fazer a associação de fatos e processos geomorfológicos, descobrindo quais os fatores estruturais e morfológicos que atuam na evolução da drenagem da bacia, resultando no produto final o mapa geomorfológico da área, e na síntese conclusiva sobre os fatores litoestruturais e litotectônicos atuantes na evolução fluvial dos canais. Neste artigo, somente os fatores relacionados à importância dos dobramentos de fundo e suas implicações geomorfológicas no condicionamento da evolução da drenagem serão apresentados, sendo que conclusões de fatos geomorfológicos sobre a bacia do Rio Benevente não serão apresentadas.

\section{Localização da área em estudo e estruturação litológica e tectônica \\ O estudo foi realizado na bacia} hidrográfica do Rio Benevente que está localizada no sul do Estado do Espírito Santo (Figura 1), entre os meridianos de $41^{\circ} 00^{\prime}$ e $40^{\circ} 30^{\prime} W G$ e os paralelos $20^{\circ} 00^{\prime}$ e $20^{\circ} 48^{\prime}$ de latitude sul, abrangendo os municípios de Anchieta, Alfredo Chaves, Domingos Martins, 
Piúma, Rio Novo do Sul e Guarapari e com uma área de aproximadamente 1.260 km².

As cabeceiras de drenagem que formam as nascentes principais desta bacia encontram-se na região da Pedra do Alto do
Redentor, após o distrito de Urânia, originando o Córrego do Redentor que, nas proximidades deste distrito, passa a receber o nome de Rio Benevente. Este rio deságua diretamente no Oceano Atlântico no município de Anchieta.

Figura 1 - Localização da bacia hidrográfica do Rio Benevente

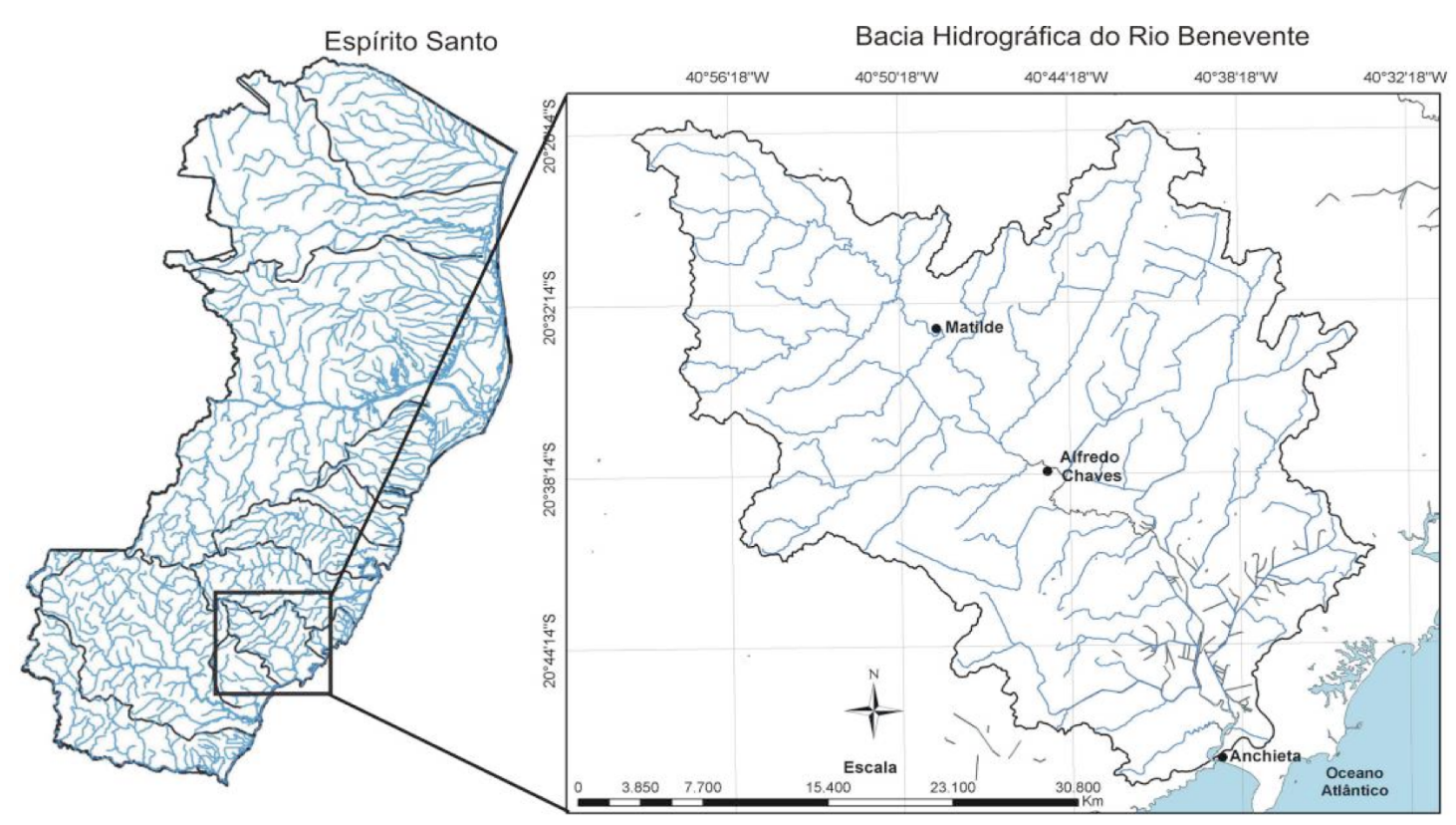

Elaboração: Roberto Vervloet.

Segundo a classificação climática de Koeppen, a região se encontra sob o predomínio dos tipos climáticos Aw (úmido com estação chuvosa no verão e seca no inverno), Am (úmido, sem estação seca pronunciada) e Cf (úmido, sem estiagem), caracterizando clima tropical úmido típico. As chuvas no interior da bacia alcançam, em alguns anos, médias pluviométricos de até $2.200 \mathrm{~mm}$, ao passo que próximo ao litoral caem para $1.500 \mathrm{~mm}$ (VERVLOET, 2009).

Uma parte da rede de drenagem dessa bacia escoa sobre as rochas metamórficas do Complexo Paraíba do Sul (quartzitos associados a gnaisses granatíferos e biotita-hornblenda gnaisse), sobre rochas Intrusivas $\operatorname{Sin}$ a Tarditangenciais (ortognaisses enderbíticos a tonalíticos de composição granítica, granodiorítica e quartzo-monzodiorítica), Intrusivas Tardi-a-Pós-Transcorrentes (dioritos, granodioritos, quartzo-monzodiorito, microclina granito e muscovita-biotita granito). A outra parte escoa sobre os depósitos do Grupo Barreiras (sedimentos areno-argilosos e argiloarenosos) e sedimentos Quaternários (depósitos argilosos e argilo-arenosos fluviais e fluviomarinhos) (FÉBOLI, 1993).

Os conhecimentos mais recentes sobre a evolução das estruturas Proterozoicas da região e áreas próximas foram estudados por Almeida (1977), Heilbron et al. (2004), Sadowski (1983), Tupinambá (1999), Delgado et al. (2003), Mendes et al. (1997), 
Mendes et al. (1999), Mendes et al. (2002), Féboli et al. (1993a; 1993b), Viera (1993), Vieira et al. (1997), Wiedemann et al. (1986), Wiedemann (1992), Wiedemann (1993), Wiedemann e Mendes (1987), Munhá et al. (2005), Vauchez et al. (1992) e Moraes et al. (2004) que compartimentaram a região de acordo com as províncias geotectônicas que deram origem à Orogênese Brasiliana.

Para averiguar a organização dessas estruturas, a partir de uma escala mais detalhada, de forma a investigar as implicações geomorfológicas dos dobramentos de fundo, bem como entender a distribuição e raio de atuação dos mesmos, é apresentado o mapa geológico simplificado da bacia, com o quadro tectônico Tardi-a-Pós-Transcorrência (Figura 22), modificado de Féboli (1993a) e Vieira (1993), com base nos conhecimentos trazidos pelos trabalhos citados e informações de campo.

Figura 2 - Mapa geológico simplificado da bacia do Rio Benevente

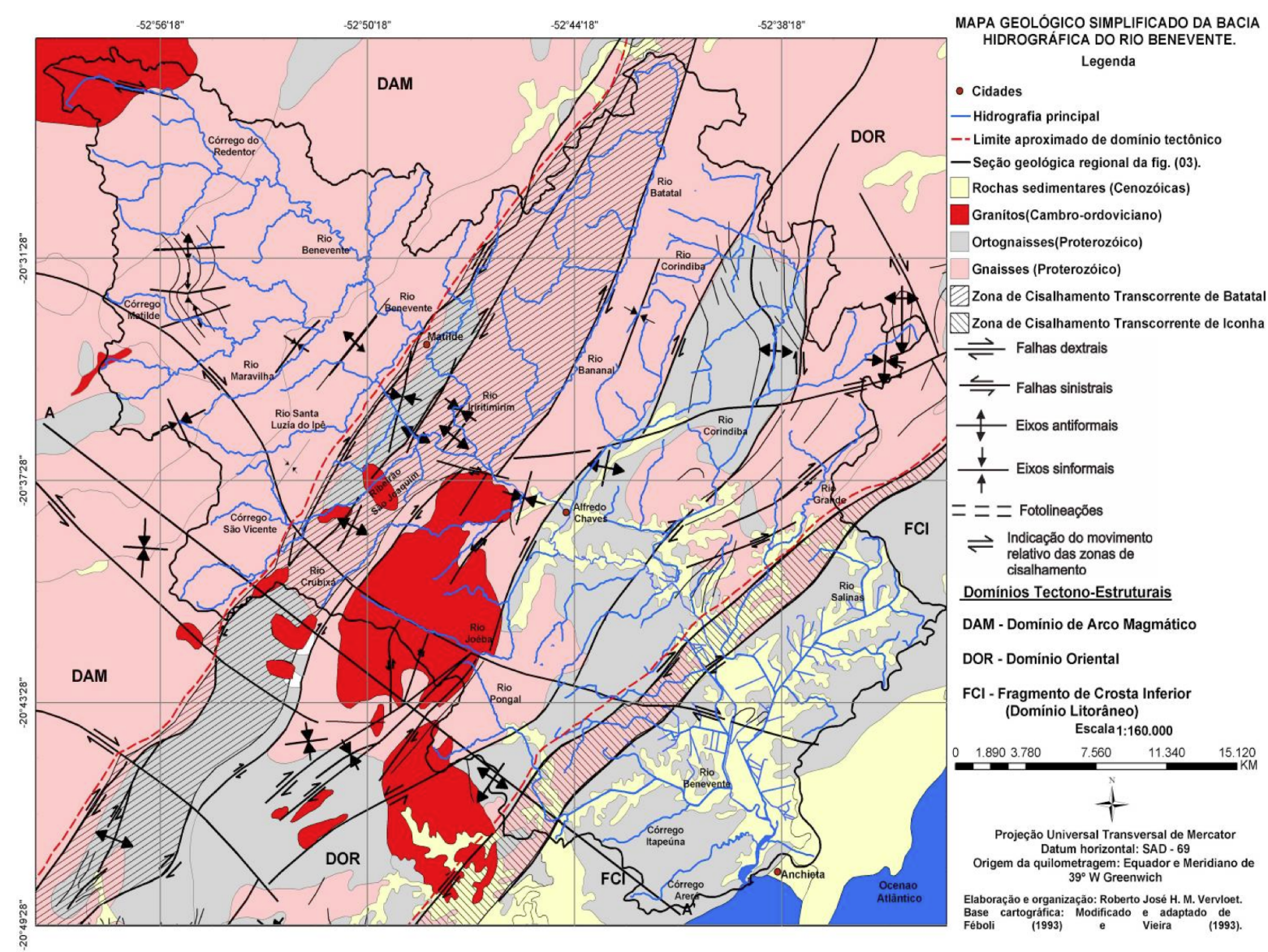

Na Figura 2, vê-se a distribuição das litoestruturas herdadas dos eventos do Proterozoico e a maneira como se dispõem os dobramentos de fundo, que vão estabelecer as repercussões geomorfológicas nos compartimentos de relevo e na evolução da drenagem que serão discutidos mais adiante.
Essa organização Proterozoica pode ser dividida em três grandes domínios tectono-estruturais (VIEIRA, 1993), que respondem pela estruturação tectônica regional: o domínio de arco magmático (DAM), o domínio oriental (DOR) e o fragmento de crosta inferior (FCI). 
Esses domínios geotectônicos tiveram origem durante a formação da grande Província Mantiqueira de Almeida (1977), na Orogênese Brasiliana, mais precisamente, com a formação dos Orógenos Araçuaí e Ribeira de Heilbron et al. (2004). Eles estão limitados por expressivas zonas de cisalhamento transcorrentes dextrais que se formaram em um regime dúctil. Duas são de grande importância na região e se dispõem na área da bacia em sentido diagonal, sendo uma a Zona de Cisalhamento Iconha (ZCI) que se direciona no sentido NE-SW e tem uma faixa de largura mais estreita, e a outra a Zona de Cisalhamento Batatal (ZCB), Féboli (1993a; 1993b), que tem direção NNE-SSW.

A gênese dos dobramentos de fundo está associada à formação dessas zonas de cisalhamento, o que os torna muito complexos, sobretudo, porque a bacia em estudo, está em uma região de transição entre os Orógenos Ribeira e Araçuaí de Heilbron et al. (2004), sendo difícil precisar quais os modelos geotectônicos que seriam responsáveis pelo relevo, pois as características desses Orógenos se sobrepõem na região, caracterizando uma zona de transição de grande complexidade entre Orógenos Proterozoicos.

Entretanto, é plausível associá-los à etapa de colisão continental designada colisão II por Heilbron (2004), que teria acontecido por volta de $580 \mathrm{Ma}$, resultando no empilhamento dos terrenos do Orógeno Ribeira de leste para oeste-noroeste. Essa colisão teria sido oblíqua, com a deformação principal exibindo clara partição da deformação entre zonas com predomínio de encurtamento crustal e zonas com componente transpressivo dextral. Fato que predominou durante a estruturação do Orógeno Ribeira, com formação de amplas lascas de cavalgamento, completadas por escamas de cavalgamento de amplitudes locais e regionais. Nessa colisão oblíqua, podem ter sido geradas também as grandes falhas transcorrentes da região, como exposto nos modelos geotectônicos trabalhados por Heilbron et al. (2004.), Wiedemann et al. (1986), Wiedemann (1992; 1993), talvez num provável regime dúctil-rúptil.

$$
\text { As lascas e/ou escamas de }
$$
cavalgamento estão também relacionadas a uma fase tangencial, acompanhada de metamorfismo regional e migmatização, evidenciada por essas zonas de cisalhamento que respondem pelas escamas de cavalgamento, segundo Vieira (1993). É provável que seja a intensa deformação resultante desta colisão II que originou os dobramentos de fundo. A organização destes em sub-superfície pode ser visualizado no perfil da Figura 3, com características apertadas e isoclinais, forte xistosidade, em alguns locais milonítica, e lineação de estiramento. 
Figura 3 - Seção geológica regional evidenciando a organização e disposição dos dobramentos de fundo. (Para localização aproximada da seção, ver Figura 2.)

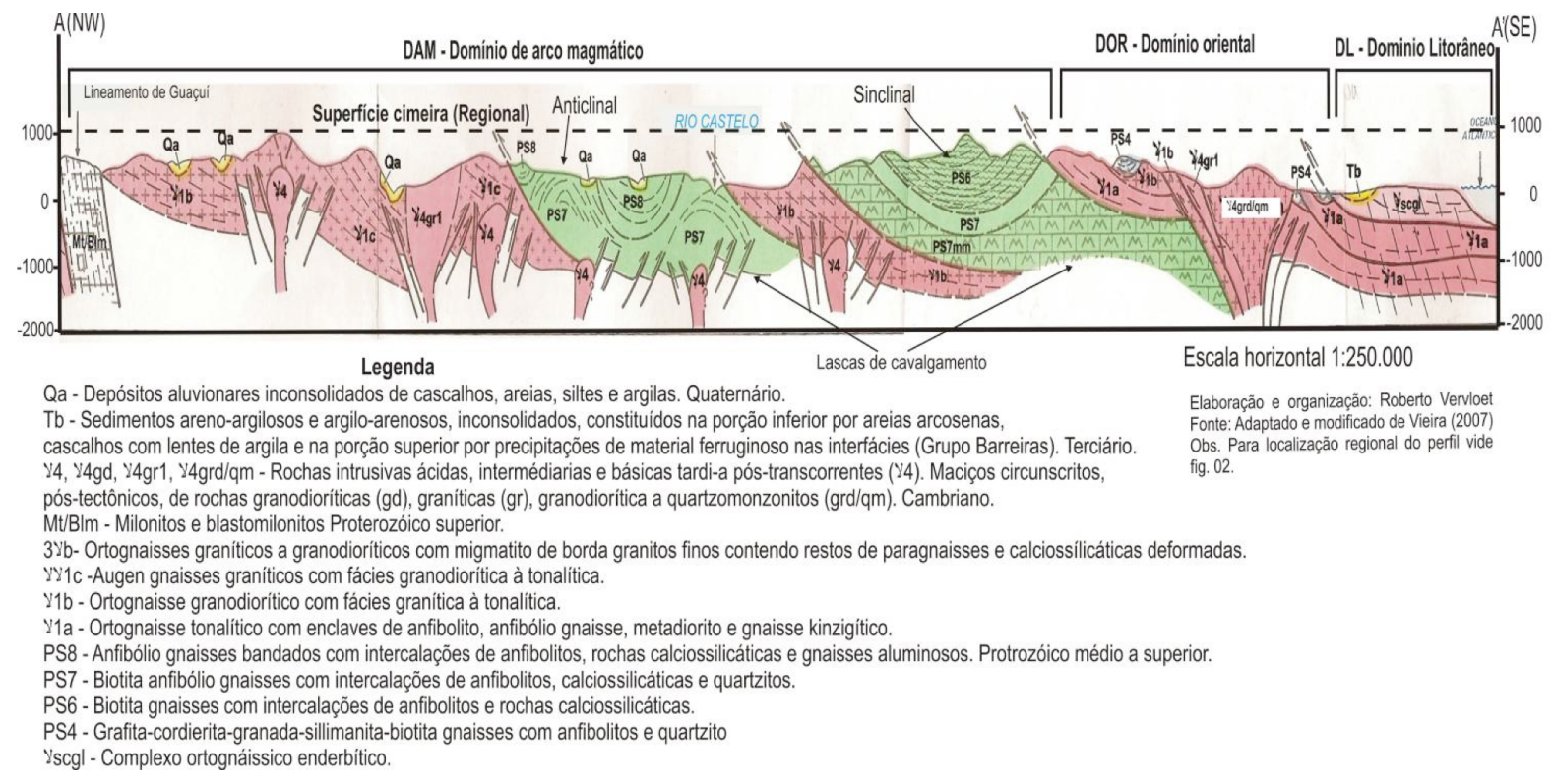

Os sistemas de falhas transcorrentes da região também teriam sido gerados nesta colisão, talvez, numa fase dúctil-rúptil posterior. Diversas suítes granitoides originaram-se do espessamento crustal oriundo desse processo de colisão, Wiedemann et al. (1986), Wiedemann (1992; 1993), tais como os granitoides da Suíte Intrusiva Espírito Santo que interfere as ZCB e ZCI. Dobras suaves de grande amplitude de onda, refletindo antiformes e sinformes abertas, geralmente posicionadas em paralelo às $Z C B$ e ZCI do mapa da Figura 2, estão relacionadas à fase transcorrente (VIEIRA, 1993).

Nas zonas de contato entre esses granitoides e outros litotipos também foram geradas dobras de amplitude local. É preciso deixar claro que esta estruturação tectônica teve origem durante os eventos do Proterozoico, como atestam os trabalhos citados.

\section{Resultados e discussão: a precedência de Francis Ruellan}

A gênese da ZCI, da ZCB e dos domínios tectono-estruturais da bacia durante 0 Proterozoico teve como repercussão a formação dos dobramentos de fundo, o qual Francis Ruellan (op. cit.), de forma pioneira, considerava fundamental para entender a compartimentação geomórfica da fachada atlântica do país.

As considerações das propriedades tectônicas dos dobramentos de fundo que geram as porções de grandes dobras anticlinais e sinclinais ao longo da fachada atlântica do Brasil deve ser uma variável chave para o entendimento da evolução geomórfico-estrutural das bacias hidrográficas que se instalaram a partir do litoral em direção ao interior do país. Esse fato era muito bem assinalado por Ruellan em suas pesquisas, mas foi num ensaio pioneiro, com o título $O$ escudo brasileiro e os dobramentos de fundo (Ruellan, 1952), que o autor apresentou a repercussão geomorfológica dessas grandes dobras. 
Certamente, foi o primeiro pesquisador a observar a repercussão e participação dos dobramentos de fundo na gênese dos grandes compartimentos de relevo do escudo brasileiro, abrindo espaço para que em escala local e regional, fossem aplicadas as suas observações projetadas para espaços subcontinentais.

Nesse trabalho de 1952, Ruellan trata das fácies de controle estrutural da topografia condicionada pelas estruturas mais resistentes, os dobramentos de fundo e os períodos de estabilidade do escudo, pela percepção de épocas de maior arrasamento das estruturas por processos erosivos longos. Tais processos de arrasamento teriam origem por meio de eventos de epigenia e superimposição hidrográfica, sobre rochas de alta resistência litológica.
Na bacia do Rio Benevente, tais fatos geomórficos podem ser observados in loco e diretamente e foram cartografados. Fundamentalmente, os dobramentos de fundo atuam na evolução da drenagem desta bacia, e, por sua vez, no condicionamento do relevo, através de dois importantes fatores condicionantes que serão discutidos: o dos setores de menor resistência à dissecação fluvial linear, oferecidos pelos sistemas de falhas proterozoicas e eixos de anticlinais em processos de exumação e dissecação pela drenagem; e o dos sistemas de knickpoints que estabelecem os níveis de base gerados pelo balanço entre resistência à erosão, por meio de soleiras rochosas e a dissecação linear fluvial realizada nos canais fluviais.

Figura 4 - Modelo digital de terreno da bacia evidenciando a distribuição espacial dos anticlinais e sinclinais de fundo

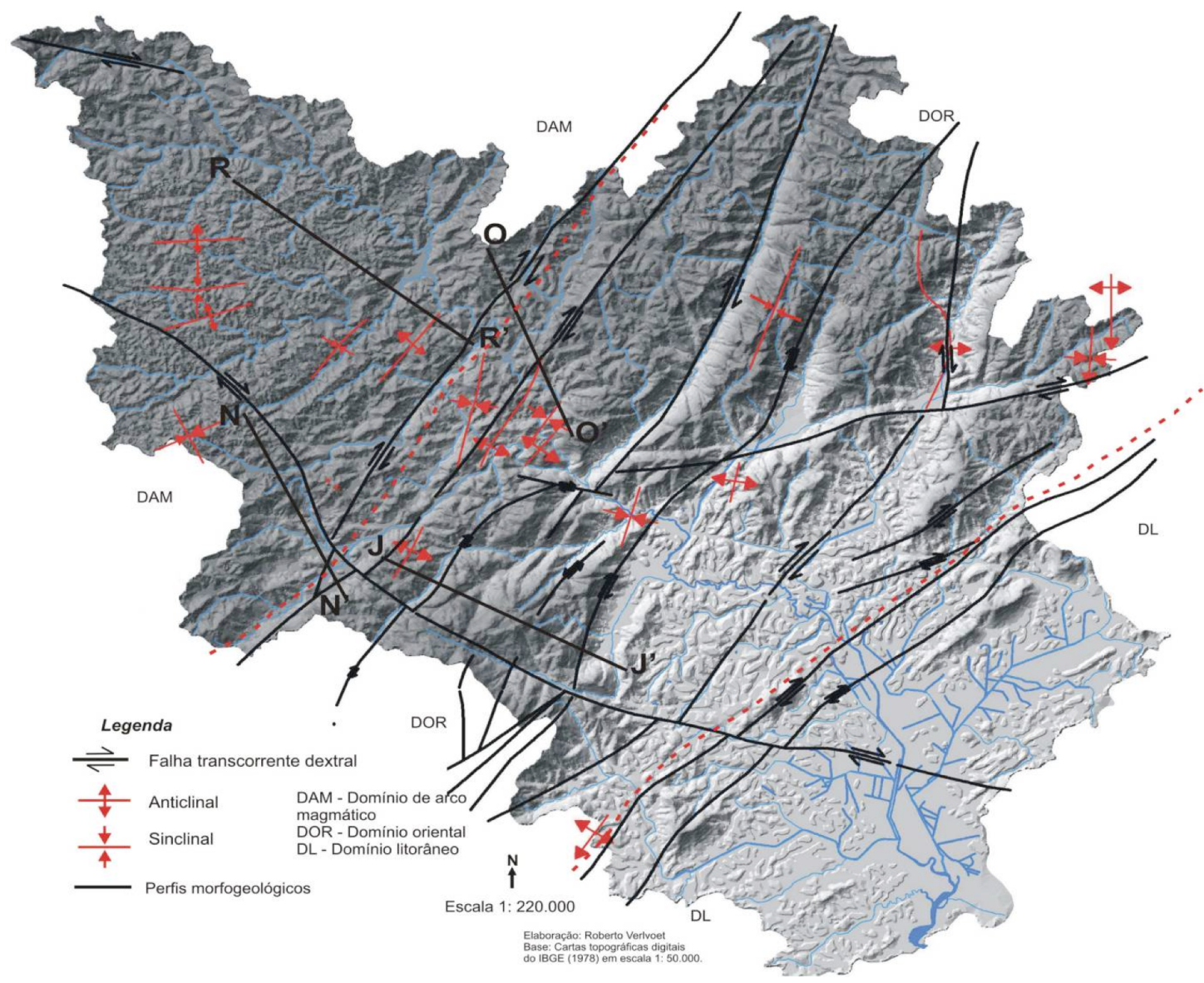


A Figura 4 apresenta o Modelo Digital de Terreno (MDT) da bacia com a localização espacial dos anticlinais e sinclinais, dos perfis morfogeológicos que serão apresentados e os sistemas de falhas transcorrentes dextrais de origem Proterozoica, cuja grande maioria segue a direção SSO-NNE, e, em menor, a NNW-SSE. Os perfis podem evidenciar melhor a repercussão geomorfológica desses dobramentos de fundo e sua influência na compartimentação morfológica.

Eles foram construídos por meio da associação entre dados de foliação e mergulhos das estruturas coletados no campo e a compartimentação e subcompartimentação morfológica da bacia.

Assim, é possível visualizar os processos de encaixamento da drenagem por meio da dissecação dos eixos das anticlinais e alçamento das sinclinais. É preciso ter em mente que esse processo de encaixamento da drenagem com consequente dissecação dos anticlinais e alçamento dos sinclinais, vem sendo realizado à custa de processos de superimposição hidrográfica pelo canal fluvial Rio Benevente. É por uma dissecação pronunciada das estruturas, a partir de uma superfície de cimeira regional, nivelada em cerca de 1.000 metros de altitude, como se vê na Figura 3 e no perfil da Figura 5, que os rios vêm seccionando estruturas orientadas para NE e NNE e, ao mesmo tempo, exumando essas estruturas. Essa exumação pode ser vista também no perfil da Figura 5, cuja foto mostra o Rio Benevente seccionando morros dissecados com linha de crista orientada para $\mathrm{N}$, num dos mais evidentes processos de superimposição hidrográfica da região.

Outro fato importante a assinalar é que na cartografia geomorfológica da bacia, os morros dissecados (Md) estão sempre associados às zonas de anticlinais em processos de exumação e dissecação. O interessante a notar é que esse perfil fica na porção central da bacia, num setor onde se veem a distribuição espacial e a melhor preservação dessa superfície cimeira que, em outros lugares, está profundamente dissecada. Ela marca o nível regional de dissecação.

Também se observam nesse perfil as zonas preferenciais de encaixamento da drenagem, condicionadas pelas falhas transcorrentes dextrais. Entretanto, deve-se ter cuidado ao tomar essas falhas como zonas de fraqueza para o encaixamento e a dissecação pela drenagem, pois nem todas funcionam como zonas de fraqueza para gênese dos vales pela drenagem. Isso pode ser mais bem entendido no perfil da Figura 6.

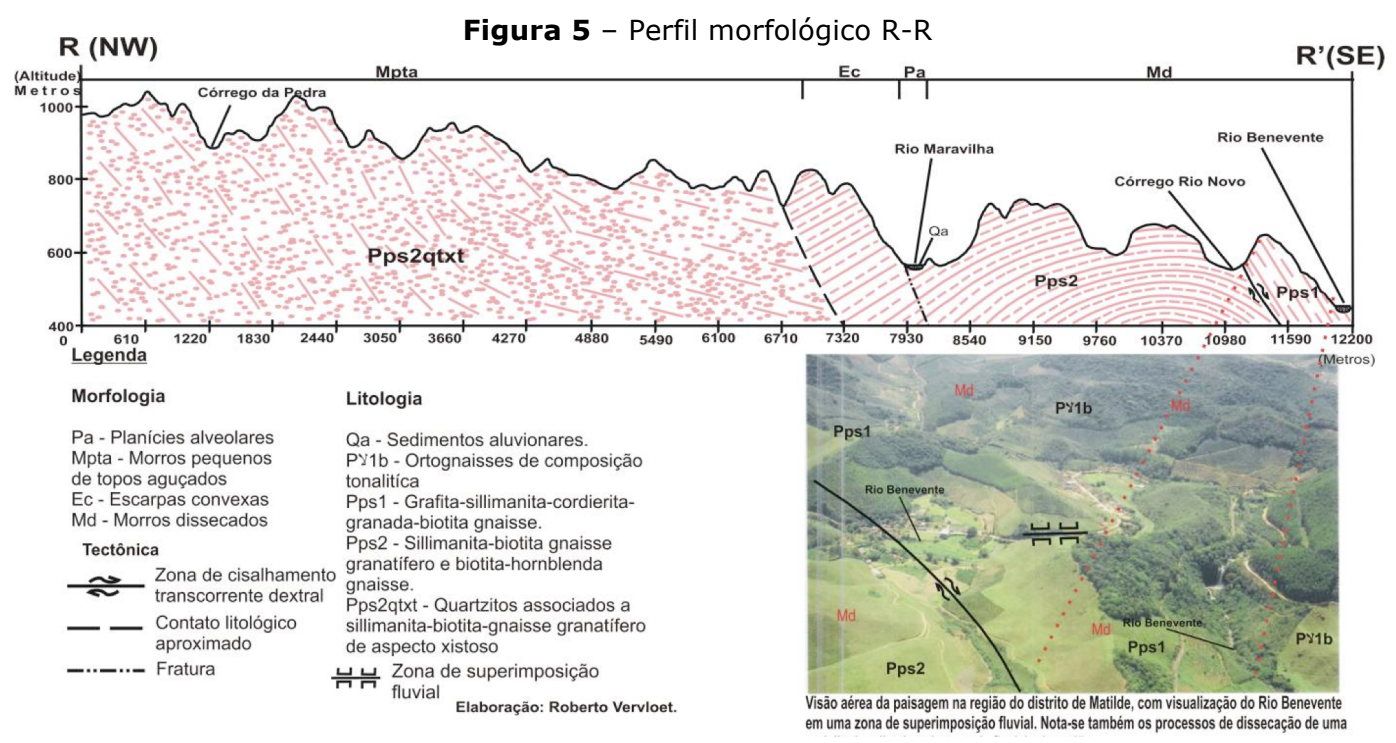


Nesse perfil, é possível observar o Ribeirão São Joaquim e o Rio Santa Luzia do Ipê dissecando setores que não estão associados a zonas preferenciais de fraqueza, dado, supostamente, pelas falhas transcorrentes.

Figura 6 - Perfil morfogeológico N-N

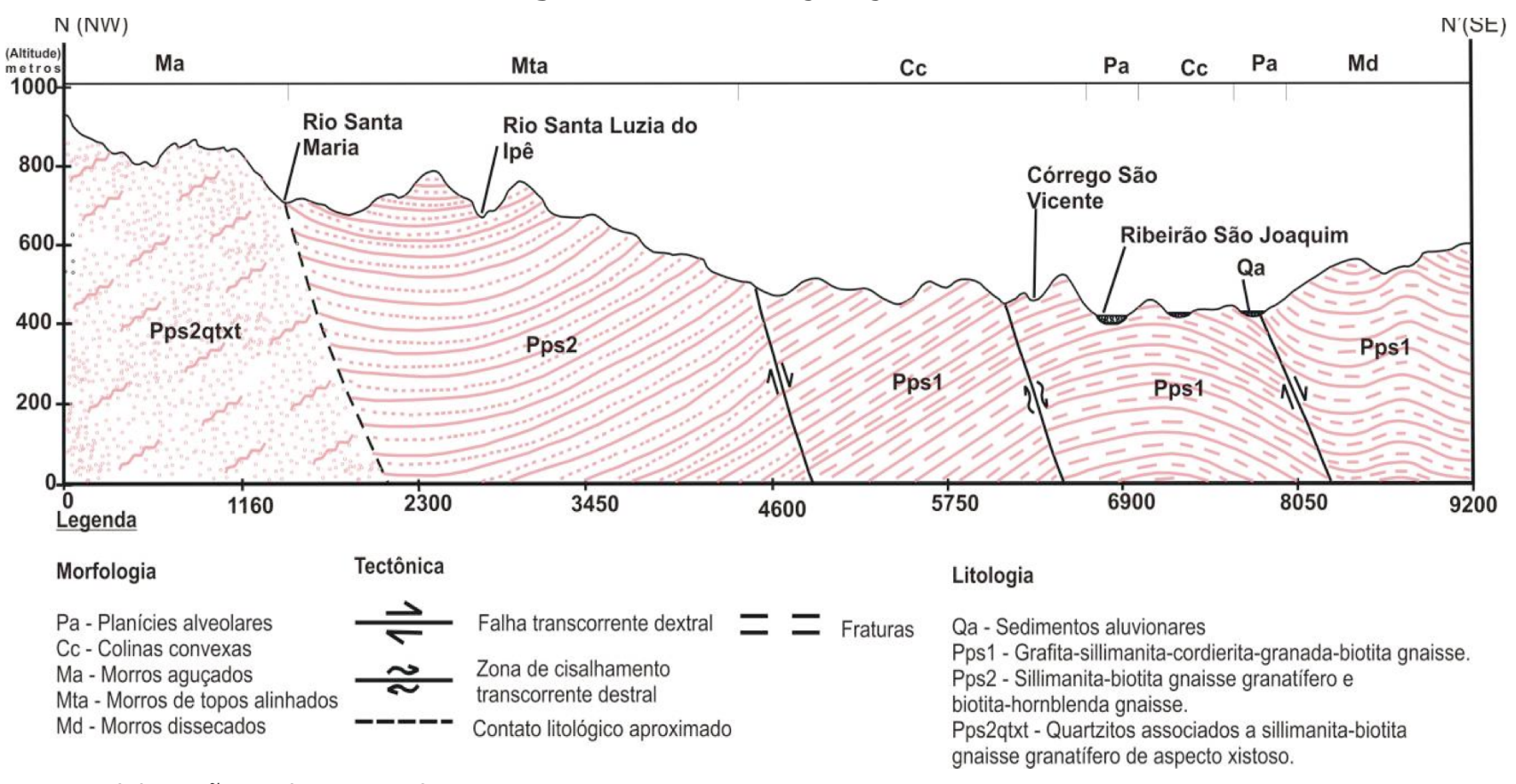

Elaboração: Roberto Vervloet.

Foi dito anteriormente que os sistemas de falhas seriam um dos principais fatores condicionantes da drenagem, no entanto, é preciso ponderar essa questão, pois a evolução da drenagem, com consequente dissecação da superfície e evolução dos vales, somente ocorre relacionada a outro importante fator condicionante que são os sistemas de knickpoints. Eles vão estabelecer os níveis de base locais e regionais no desenvolvimento das vertentes e dos vales e influenciar fortemente os perfis longitudinais dos rios, estando profundamente associados ao que se denominou de "miolos" de dobramentos. Esses sistemas de knickpoints controlam a evolução regressiva da drenagem, aparecendo ao longo dos perfis longitudinais dos canais que atravessam estes dobramentos que, na maioria das vezes, têm os seus eixos orientados para N, NE e NNE.
Assim, eles são responsáveis pelos níveis de base, tanto locais quanto regionais.

Um importante nível de base regional é o que pode ser visto no perfil da Figura 7, que apresenta a calha do Rio Iriritimirim com afloramento de gnaisses migmatizados do Complexo Paraíba do Sul. Pode-se observar que este rio disseca a borda de uma anticlinal, ao mesmo tempo responde pelo alçamento de uma sinclinal situado na porção adjacente. É possível observar também o escalonamento dos vales provenientes da dissecação deste mesmo rio situados paralelamente no perfil. Um situa-se no interior da sinclinal e o outro é gerado em uma zona de falha transcorrente, em contato litológico entre ortognaisses e os gnaisses do Complexo Paraíba do Sul. Esse escalonamento de vales é derivado do processo de evolução diferencial feito por 
esse rio sobre diferentes litotipos de diferentes resistências litológicas e, ao mesmo tempo, controlado por regressão de knickpoints associados a diferenças litológicas e a complexos processos hidráulicos de incisão fluvial. Em campo, constatou-se que o perfil longitudinal desse rio apresenta um escalonamento profundamente condicionado por esses processos diferenciais e, mais importante do que esse processo de evolução diferencial, foi perceber a forte correspondência espacial entre a posição dos eixos de dobramentos e os knickponts aflorantes nas calhas fluviais.
Isso ocorre porque, como atesta, os processos de colisão ocasionaram intenso metamorfismo e consequente migmatização das rochas, quando da colisão orogenética (HEILBRON, 2004). Esse metamorfismo e essa migmatização certamente foram acompanhados de anatexia em alguns pontos no interior das grandes dobras, gerando alinhamentos de rochas duras e de alta resistência litológica no interior dos dobramentos. Sabemos que se trata do interior dos dobramentos pela posição espacial desses knickpoints, posicionados nos paleoeixos dos antiformes e sinformes, e hoje aflorantes na paisagem devido à dissecação fluvial linear.

Figura 7 - Perfil morfogeológico O-O

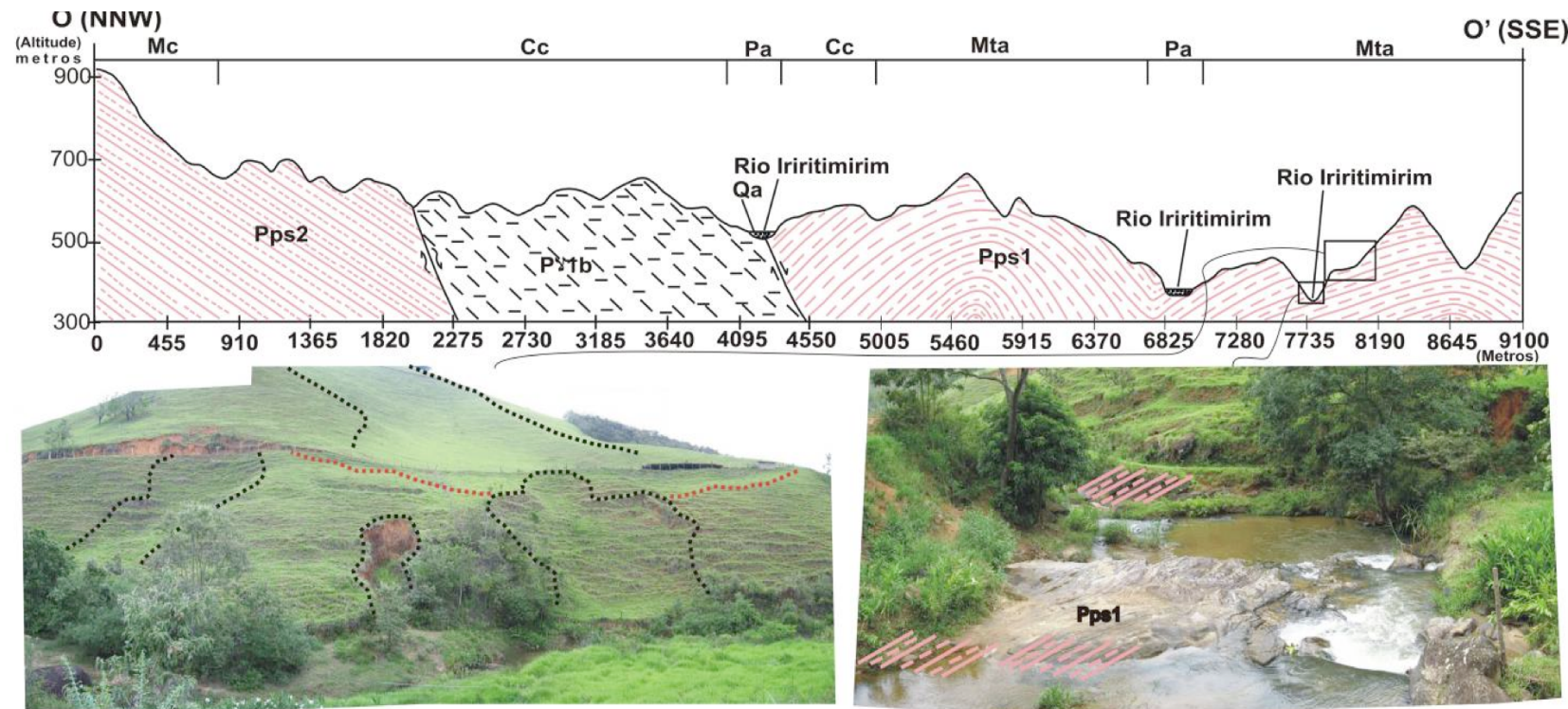

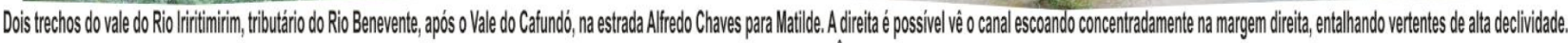
Notar o ângulo de mergulho dos gnaisses migmatizados da unidade Pps1, em borda de sinclinal em processo de alçamento. Ângulo de visada da foto de NE. SW. A escuerda é possivel observar o mesmo vale logo a jusante do ponto

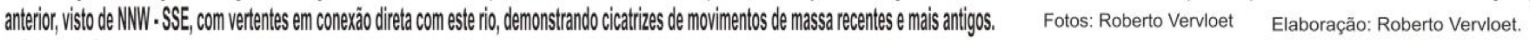
Legenda

\begin{tabular}{|c|c|c|}
\hline $\begin{array}{l}\text { Morfologia } \\
\text { Pa - Planícies alveolares } \\
\text { Cc - Colinas convexas } \\
\text { Mta - Morros de topos alinhados } \\
\text { Mc - Morros convexos }\end{array}$ & & $\begin{array}{l}\text { Ruptura geométrica } \\
\text { de vertente } \\
\text { Cicatriz derivada } \\
\text { de movimento de } \\
\text { massa. }\end{array}$ \\
\hline
\end{tabular}

É dessa forma que os dobramentos de fundo vão também condicionar a evolução dos canais fluviais, por meio de alinhamento de rochas duras situadas no "miolo" das grandes dobras, as quais ao sofrerem dissecação pela drenagem, acabam

$$
\text { Litologia Tectônica }
$$

Qa - Sedimentos aluvionares Py1b - Ortognaisses de composiçao tonalítica Pps1 - Grafita-sillimanita-cordierita-granada-biotita Ps2 - Sillimanita-biotita gnaisse granatifero e

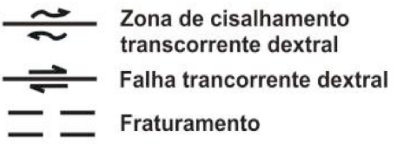

funcionando como verdadeiros sistemas de knickpoints que vão evoluir através do balanço entre erosão fluvial hidráulica regressiva e a resistência rochosa a esta erosão. Não é por acaso que os dois vales do Rio Iriritimirim, vistos no perfil da Figura 7, 
estão estabilizados atualmente na borda interna de uma anticlinal e sinclinal em exumação e processo de alçamento.

$\mathrm{Na}$ foto esquerda da Figura 7, é possível observar também cicatrizes de movimentos de massa que respondem pela formação de rupturas geométricas de vertentes. Tal processo ocorre associado ao desenvolvimento da cobertura pedológica em rochas posicionadas em flancos mergulhantes das bordas dos anticlinais e sinclinais, uma vez que estas rochas, devido a sua estrutura foliada e migmatizada parcialmente, e ao mesmo tempo de alto mergulho, permitem a gênese, dentro da cobertura pedológica, de superfícies de rupturas. Tais superfícies se rompem em determinado momento da evolução dos canais fluviais, quando estes estabelecem incisão linear nas margens das calhas fluviais, provocando rebaixamento do nível de base local e consequente mudança de equilíbrio nas vertentes. Para manter este equilíbrio há a formação de superfícies de ruptura que geram movimentos de massa, diminuindo o ângulo de inclinação das vertentes, e provocando reafeiçoamento das mesmas e dos vales fluviais. Tais processos e eventos são muito ocorrentes nas zonas de bordas de anticlinais e sinclinais, distribuídos ao longo da bacia.

Os dobramentos vão estar associados também às zonas de contato entre rochas intrusivas e as metamórficas encaixantes, como se observa pelo perfil da Figura 8 . Notar a dissecação fluvial linear realizada pelo Rio Crubixá na porção superior da anticlinal associada ao contato litológico entre as metamórficas do Complexo Paraíba do Sul e as intrusivas do Maciço Iconha. Trata-se de uma zona preferencial de encaixamento da drenagem que tem o vale fluvial desenvolvido pelo controle realizado pelos sistemas de knickpoints que estão dispostos ao longo do perfil longitudinal deste rio.

Figura 8 - Perfil morfogeológico J-J

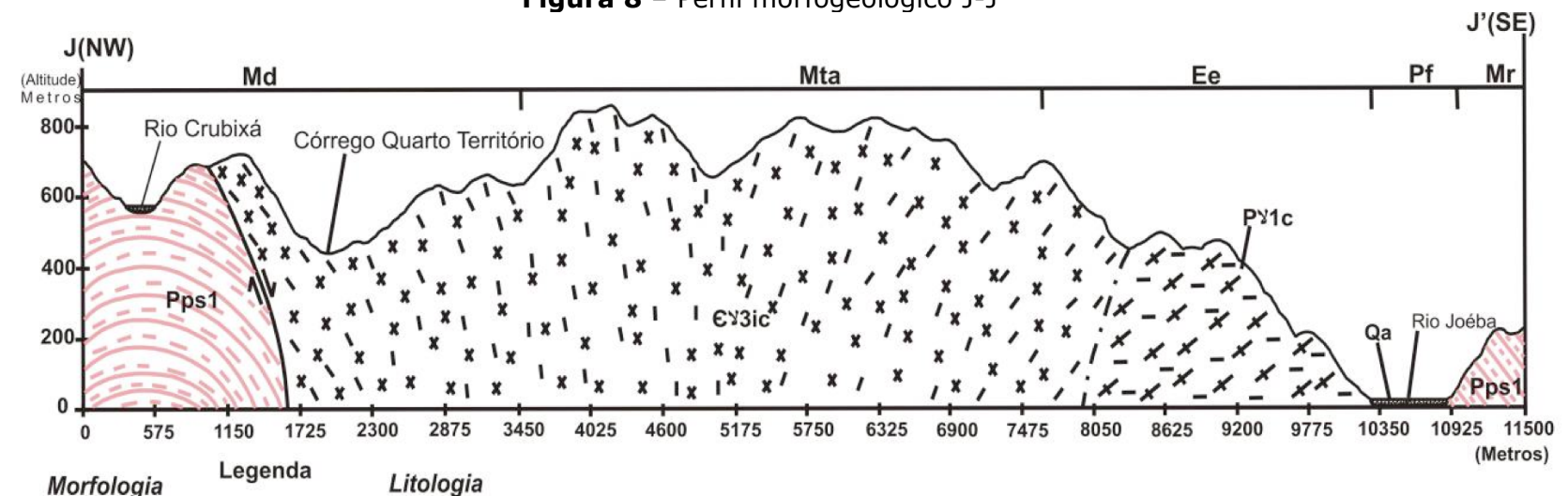

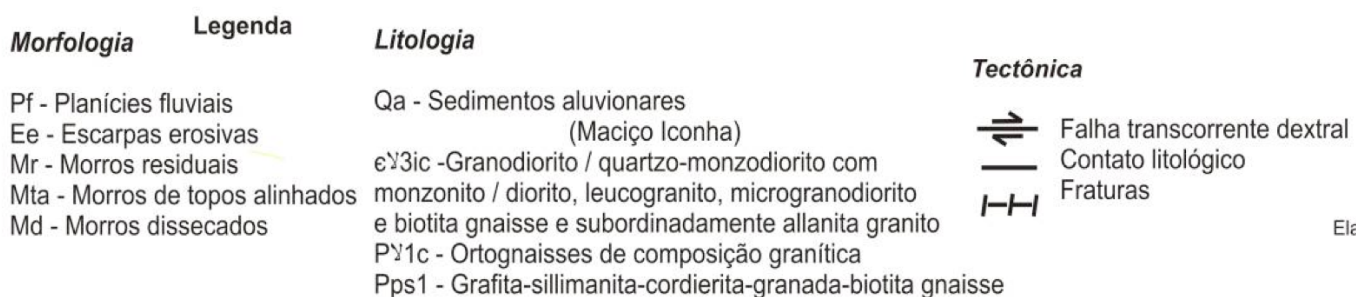


Nota-se também que o Córrego Quarto Território, mais rebaixado, gera um vale em setor de contato litológico associado a uma falha transcorrente dextral. Há ainda outras interessantes evidências sobre a participação dos dobramentos de fundo no condicionamento da drenagem, entretanto, somente tais fatores são aqui apresentados, por serem mais elucidativos e, portanto, considerados mais importantes.

Os dobramentos de fundo foram gerados, portanto, em profundidades variadas da crosta e estão hoje aflorantes na paisagem, devido ao soerguimento Cenozoico do escudo brasileiro, seguido de longos processos erosivos concomitantes que controlam a evolução atual da drenagem da bacia, através dos sistemas de knickpoints. Ao mesmo tempo, eles controlam também os processos de exumação das estruturas e condicionam a dissecação da drenagem, influenciando na compartimentação morfológica.

Não há dúvida quanto ao fato de terem sofrido soerguimento ao longo do Cenozoico, pois estudos com traços de fissão em apatitas realizados por Vignol-Lelarge et al. (1994) no Arco de Ponta Grossa e Gallagher et al. (1994) na Serra do Mar Paranaense, e Chemale Jr. e Hadler Neto (2005) na região serrana do Espírito Santo, bem como outros autores, vêm confirmando esses processos de soerguimento ocorridos no final do Cretáceo e início do Paleoceno. Entretanto, esse soerguimento veio acompanhado, certamente, de uma forte dissecação, condicionada por esses fatores estruturais. Embora os estudos com traços de fissão em apatitas sejam realizados em áreas distantes da bacia pesquisada, eles corroboram os resultados dos estudos de litoquímica realizados por Féboli (1993a; 1993b), na região da bacia, que indicaram, também, uma gênese profunda para as rochas ( $>30-20 \mathrm{~km}$ de profundidade) dobradas da região.

Não se pode deixar de levar em consideração o fato de que essas rochas estiveram em um momento na subsuperfície, e atualmente afloram na paisagem geomorfológica. Este fato é de suma importância, porque a evolução do relevo Quaternário da bacia é condicionada, acredita-se, por rochas dobradas formadas no Proterozoico e que foram soerguidas na passagem do Cretáceo para o Paleoceno, estando atualmente na superfície e controlando a evolução da drenagem, através dos fatores condicionantes relacionados aos dobramentos de fundo. Entretanto, o mais interessante desses estudos, em traços de fissão em Apatitas, não é trazer evidências sobre os processos de soerguimento do escudo, certamente, através do deslocamento de blocos falhados, mas, sim, em ter noção da quantidade de material desnudado da superfície pelos processos erosivos ao longo do tempo geológico. Fato que não é muito bem avaliado por esses trabalhos. Vignol-Lelarge et al. (1994), por exemplo, fala em até $2,5 \mathrm{~km}$ de denudação na região do Arco de Ponta Grossa, sem fazer nenhuma menção sobre como seria essa história erosiva.

Não foram encontrados até 0 presente momento na região da bacia, indicadores cinemáticos de reativação dos sistemas de falhas Proterozoicas, realizados durante o Quaternário. Por isso não é possível ainda conjecturar sobre prováveis implicações neotectônicas na evolução desta drenagem e por consequência no relevo, 
embora muitos trabalhos realizados em outras regiões do Brasil tenham apresentado indicadores cinemáticos em depósitos holocênicos. Mesmo que no futuro, tais indicadores sejam encontrados, não basta simplesmente associar os compartimentos de relevo com tais deslocamentos de blocos, através da reativação das falhas, pois é preciso que haja desnivelamento dos sistemas de níveis de base, sustentados pelos knickpoints nas rochas de alta resistência, para ocorrer erosão regressiva pelos canais fluviais, e assim, reafeiçoamento do relevo. É por isso que não há grande discrepância entre os relevos regionais, que estão nivelados em uma cota média de $1.000 \mathrm{~m}$, sendo essa a altitude média da superfície cimeira regional (Figura 3 ).

Se tais knickpoints em rochas de alta resistência a erosão forem mantidos, a paisagem não se disseca, e, assim, ficam preservados os blocos planálticos e a superfície cimeira regional. Deve-se evitar também associar padrões de drenagem em treliça e ângulos retos da drenagem, em zonas de falhas, como prováveis inferências de uma tectônica moderna, pois os sistemas de fraturas e falhas de maciços cristalinos antigos (Proterozoicos) condicionam a formação, por efeito de encaixamento linear e dissecação dos canais, de um padrão de drenagem em treliça, não significando que com isso tenha havido necessariamente uma gênese tectônica ativa desse padrão hidrográfico da drenagem. Nesses casos, a interpretação por meio de uma tectônica passiva por efeito de encaixamento fluvial é mais coerente.

\section{Conclusões}

O pioneirismo das diretrizes empíricas e teóricas deixadas por Ruellan em suas pesquisas realizadas na década de 1950, sobretudo em seu trabalho sobre o escudo brasileiro, de 1952, tem sido muito negligenciado. Este artigo partiu de suas ideias pioneiras, mas não se ateve a elas.

É preocupante a desconsideração da geologia tectônica brasileira para com estudos geomorfológicos estruturais de vanguarda e pioneiros como os de Ruellan. Quando aparecem, são apenas citações de cunho histórico, com total negação das ideias pioneiras.

Corroborando as ideias de Ruellan, a configuração atual da rede hidrográfica da bacia do Rio Benevente e a maneira como ela se encaixa e disseca as estruturas dobradas reforçam a ideia de evolução dos canais altamente condicionada por uma dissecação diferencial, relacionada à anisotropia das estruturas e as diferentes fácies de resistência que as mesmas oferecem, associados ao balanço entre erosão regressiva dos sistemas de knickpoints e período de equilíbrio dos canais, devido à resistência a esses processos erosivos lineares realizados pelos canais fluviais.

Assim, tem razão Ab'Sáber (2001) quando alerta para a negligência das ideias de Francis Ruellan sobre geomorfologia regional nos atuais estudos de geologia regional e tectônica, fato que certamente empobrece a geologia e a geomorfologia brasileiras. 


\section{Referências bibliográficas}

AB'SÁBER, A. N. Megageomorfologia do território brasileiro. In: GUERRA, A. J. T.; CUNHA, S. B. (Orgs.). Geomorfologia do Brasil. 2. ed. Rio de Janeiro: Bertrand Brasil, 2001. p. 71-106.

Da participação das depressões periféricas e superfícies aplainadas na compartimentação do planalto brasileiro. Tese (Livre-docência) Faculdade de Filosofia, Letras e Ciências Humanas, Universidade de São Paulo, São Paulo: 1965.

. O relevo brasileiro e seus problemas. In: AZEVEDO, A. (Org.). Brasil, a terra e o homem: as bases físicas, v. 1. São Paulo: Nacional, 1964. p. 135-250.

ALMEIDA, F. F. M. O cráton do São Francisco. Revista Brasileira de Geociências, v. 7, n. 4, p. 349-364, 1977.

. Os fundamentos geológicos. In: AZEVEDO, A. (Org.). Brasil, a terra e o homem: as bases físicas, v. 1. São Paulo: Nacional, 1964. p. 55133.

ALMEIDA, F. F. M.; CARNEIRO, C. R. Origem e evolução da Serra do Mar. Revista Brasileira de Geociências, v. 28, n. 2, p. 135-150, 1998.

AZEVEDO JR., M. F. (1991). Integração entre o preenchimento sedimentar cenozoico das bacias de Campos e Santos e a evolução tectônica e geomorfológica das áreas continentais adjacentes. Dissertação (Mestrado em Geologia) - Universidade Federal de Ouro Preto, Ouro Preto, 1991.

BIGARELLA, J. J.; ANDRADE LIMA, D.; RIEHS, P. J. Considerações a respeito das mudanças paleoambientais na distribuição de algumas espécies vegetais e animais no Brasil. Anais da Academia Brasileira de Ciências, Rio de Janeiro, v. 47 (supl.), p. 411-464, 1975.

BIGARELLA, J. J.; ANDRADE, G. O. Contribution to the study of the Brazilian Quaternary. Geol. Soc. of America, v. 84, p. 433-451, 1965.
BIGARELLA, J. J.; MOUSINHO, M. R. Considerações a respeito dos terraços fluviais, rampas de colúvio e várzeas. Boletim Paranaense de Geografia, Curitiba, n. 16/17, p. 153-197, 1965.

BIGARELLA, J. J.; AB'SABER, A. N. Quadro provisório dos fatos sedimentológicos, morfoclimáticos e paleoclimáticos na Serra do Mar paranaense e catarinense. Boletim Paranaense de Geografia, Curitiba, n. 2/5, p. 91, 1961.

BIROT, P. Esboço morfológico da região litorânea do estado do Rio de Janeiro. Notícia Geomorfológica, v. 2, p.19.

BRITO NEVES, B. B. América do Sul: quatro fusões, quatro fissões e o processo acrescionário andino. Revista Brasileira de Geociências, v. 29, n. 3, p. 379-392, 1999.

CHEMALE JR., F.; HADLER NETO, J. C. (Coords.). Termocronologia por traços de fissão em apatita: margem SE do Brasil e Uruguai. Porto Alegre: UFRGS, 2005. (Projeto Evolter, v. 4.)

COLTRINARI, L. Geomorfologia e dinâmica quaternária no Sudeste do Brasil. Revista do Departamento de Geografia, São Paulo: FFLCH-USP, n. 6, 1992.

DELGADO, I. M. et al. Geotectônica do escudo Atlântico. In: BIZZI, L. C. (Org.). Geologia, tectônica e recursos minerais do Brasil: texto, mapas \& SIG. Brasília: CPRM Serviço Geológico do Brasil, 2003. Cap. IV, p. 227-334.

DE MARTONNE, E. Problemas morfológicos do Brasil tropical atlântico. Revista Brasileira de Geografia, Rio de Janeiro: IBGE, v. 5, n. 4, p. 523-550; v. 6, n. 2 , p. 155-178, 1944-1943.

FÉBOLI, W. Progr. Lev. Geolog. Básicos do Brasil. Carta Geológica, Carta Metalogenética/Previsional, escala 1: 100.000. Folha Domingos Martins, SF. 24-V-A-III, Estado do Espírito Santo. Brasília, DNPM/CPRM, 1993a. 
- Progr. Lev. Geol. Bás. do Brasil. Carta Geológica, Carta

Metalogenética/Previsional, escala 1: 100.000. Folha Piúma, SF. 24-V-A-VI, Estado do Espírito Santo. Brasília, DNPM/CPRM, 1993b.

FREITAS, R. O. Relevos policíclicos na tectônica do escudo brasileiro. Boletim Paulista de Geografia, v. 7, p. 3-19, 1951a.

. Ensaio sobre o relevo tectônico do Brasil. Revista Brasileira de Geografia, Rio de Janeiro, v. XIII, n. 2, p. 171-222,1951b.

FILIZOLA, H. F. O papel da erosão geoquímica na evolução do modelado da bacia de Taubaté - SP. Tese (Doutorado em Geografia Física) Faculdade de Filosofia, Letras e Ciências Humanas, Universidade de São Paulo, São Paulo, 1993.

FILIZOLA, H. F.; BOULET, R. Evolution and opening of closed depressions developed in a quartz-Kaolinitic sedimentary substratum at Taubaté basin (São Paulo, Brazil), and analogy to the slope evolution.

Geomorphology, v. 16, p. 77-86, 1996.

. Une évaluation de la vitesse de l'érosion géochimique à partir de l'étude de dépresions fermées sur roches sédimentaires quartzokaoliques au Brésil. Comptes Rendus de I'Académie des Sciences, Paris, v. 316, sér. II, p. 693-700, 1993.

HASUY, Y. Neotectônica e tectônica ressurgente no Brasil. In: WORKSHOP NEOTECTÔNICA E SEDIMENTAÇÃO CONTINENTAL CENOZOICA DO SE DO BRASIL, 1., Belo Horizonte. Anais..., SBG/MG, 1990. Boletim 11, p. 1-32.

HEILBRON, M. et al. Província Mantiqueira. In: MANTESSO-NETO, V. et al. (Orgs.). Geologia do continente sul-americano: evolução da obra de Fernando Flávio Marques de Almeida. Beca: São Paulo, 2004. p. 203-235.

GALLAGHER, K.; HAWKESWORTH, C. J.; MANTOVANI, M. S. M. The denudation history of the onshore continental margin of SE Brazil inferred from apatite fission track data. Journal of
Geophysical Research, v. 99, n. B9, p. 18117-18145, sept. 10, 1994.

KING, L. A geomorfologia do Brasil oriental. Revista Brasileira de Geografia, Rio de Janeiro, v. 18, n. 2), p. 147266, 1956.

LEOPOLD, L. B.; LANGBEIN, W. B. Asociación e indeterminación en geomorfología. In: ALBRITTON, C. C. J. (Ed.). Filosofía de la Geología. México/ Argentina/España/Chile: Companhia Continental, 1970.

MENDES, J. C. et al. Conditions of formation of charnokitic magmatic rocks from the Várzea Alegre massif, Espírito Santo, southeast Brazil. Revista Brasileira de Geociências, v. 29, p. 47-54, 1999.

MENDES, J. C. et al. Charnockitoides do maciço de Várzea Alegre: um novo exemplo do magmatismo cálcioalcalino de alto-K no arco magmático do Espírito Santo. Revista Brasileira de Geociências, v. 27 , n. 1, p. 1324, mar. 1997.

MENDES, J. C. et al. Norito e charnoenderbitos da corda do Maciço Intrusivo de Venda Nova, Espírito Santo. Anuário do Instituto de Geociências, UFRJ: Departamento de Geologia, v. 25, p. 99-124, 2002.

MORAES, R. et. al. Granulitos do Brasil. In: In: MANTESSO-NETO, V. et al. (Orgs.). Geologia do continente sul-americano: evolução da obra de Fernando Flávio Marques de Almeida. Beca: São Paulo, 2004. p. 321-345.

RAMSAY, J. G.; HUBER, M. I. The techniques of modern Sctrutural Geology. V. 2: Folds and Fractures. Academic Press, 1987.

PONÇANO, W. L.; ALMEIDA, F. F. M. Superfícies erosivas nos planaltos cristalinos do leste paulista e adjacências: uma revisão. Cadernos IG, Unicamp, v. 3 , n. 1 , p. 55-90, 1993.

\section{RICCOMINI, C. O Rift continental do} Sudeste do Brasil. Tese (Doutorado em Geologia Sedimentar) - Instituto de Geociências, Universidade de São Paulo, São Paulo, 1989. 
ROSS, J. L. S. O registro cartográfico dos fatos geomorfológicos e a questão da taxonomia do relevo. Revista do Departamento de Geografia, São Paulo: FFLCH-USP, n. 6, 1992.

- O relevo brasileiro, as superfícies de aplainamento e os níveis morfológicos. Revista do Revista do Departamento de Geografia, São Paulo: FFLCH-USP, n. 5, 1991.

RUELLAN, F. O problema geomorfogenético nos estudos dos relevos policíclicos e epicíclicos nas bordas do Atlântico.

Anais da Associação dos Geógrafos Brasileiros, São Paulo, v. VIII, tomo I, p. 379-383, 19531954.

. O escudo brasileiro e os dobramentos de fundo. Curso (Especialização em Geomorfologia) Departamento de Geografia, Faculdade Nacional de Filosofia Universidade do Brasil, Rio de Janeiro, 1952a.

- Le rôle des plis found dans le relief du boudier Sud-Americain. Comm. au Congrès. Int. de Géol. Alger., 28 p. dactyl. I carte, 1952b.

- Problemas do relevo e da estrutura do Brasil. Boletim Geográfico, Rio de Janeiro, ano IX, n. 102, p. 625628 , set. $1951 a$.

- Estudo preliminar da geomorfologia da região leste da Mantiqueira.

Boletim Carioca de Geografia, Rio de Janeiro, ano IV, n. 2/3/4, p. 5-16, 1951b.

. Evolução geomorfológica da baía de Guanabara e das regiões vizinhas.

Revista Brasileira de Geografia, $n$. 6, p. 445-508, 1944.

SAADI, A. Neotectônica da plataforma brasileira: esboço e interpretações preliminares. Geonomos, Belo Horizonte, v 1, n. 1, p. 1-15, 1993.

- Neotectônica da área de tabuleiros do sul da Bahia. Projeto Porto Seguro - Santa Cruz Cabrália. Programa Informações para Gestão Territorial. Salvador: CPRM/CBPM/SEAGRI-DDF, 2000. V. Geologia. p. 40-55.
SADOWSKI, G. R. Sobre a Geologia Estrutural de cinturões de cisalhamento continentais. Tese (Livre-docência) - Instituto de Geociências, Universidade de São Paulo, São Paulo, 1983.

TUPINAMBÁ, M. Evolução tectônica e magmática da faixa ribeira na região serrana do estado do Rio de Janeiro. Tese (DoutoradoInstituto de Geociências, Universidade de São Paulo, São Paulo, 1999.

VAUCHEZ, A. Tectônica de escape na terminação de um cráton: a faixa ribeira. In: CONGRESSO BRASILEIRO DE GEOLOGIA, 37., Boletim de Resumos Expandidos, SBG, São Paulo, p. 373-374, 1992.

VIEIRA, V. S. Programa Levantamentos Geológicos Básicos do Brasil. Carta Geológica, Carta Metalogenética/ Previsional, escala 1: 100.000. Folha Baixo Guandu, SE. 24-Y-C-V, Estado de Minas Gerais e Espírito Santo. Brasília, DNPM/CPRM, 1993.

VIEIRA, V. S. Programa Levantamentos Geológicos Básicos do Brasil. Carta Geológica, Carta Metalogenética/ Previsional, escala 1: 250.000. Folha Cachoeiro do Itapemirim, SF.24-Z-VA, Estado do Espírito Santo, Minas Gerais e Rio de Janeiro. Brasília, DNPM/CPRM, 1997.

VIGNOL-LELARGE, M. L. M.; SOLIANI JR., E.; POUPEAU, G. Datação pelos traços de fissão do domínio meridional da Serra do Mar (Arco de Ponta Grossa Brasil). In: CONGRESSO BRASILEIRO DE GEOLOGIA, 38., Camboriú, Boletim de Resumos Expandidos, SBG, V.2, p. 379-380, 1994.

VERVLOET, R. J. H. M. Condicionantes morfológicos e estruturais na dinâmica fluvial da bacia hidrográfica do Rio Benevente - Espírito Santo. Dissertação (Mestrado em Geografia Física) - Faculdade de Filosofia, Letras e Ciências Humanas, Universidade de São Paulo, São Paulo, 2009.

WIEDEMANN, C. M. The Evolution of the Early Paleozoic, Late-to Post-Collisional Magmatic Arc of the Coastal Móbile Belt, in the state of Espírito Santo, eastern Brazil. Anais da Academia 
Brasileira de Ciências, v. 65, n. 1, p. 163-181, 1993.

WIEDEMANN, C. M. Evolução magmática brasiliana do cinturão móvel Ribeira, no estado do Espírito Santo. In: CONGRESSO BRASILEIRO DE GEOLOGIA, 37., São Paulo. Anais..., 1992. p. 376-377.

WIEDEMANN, C. M.; MENDES, J. C.

Contribuição à geologia e petrografia do Complexo Intrusivo de Rio Novo do Sul. In: SIMPÓSIO DE GEOLOGIA REGIONAL RJ-ES, 1., SBG, Rio de Janeiro. Anais..., 1987. p. 109-118.

WIEDEMANN, C. M. et. al. Maciços intrusivos do sul do Espírito Santo e seu contexto regional. Revista

Brasileira de Geociências, v. 16, n. 1, p. 24-37, mar. 1986. 